\title{
Oxidative Stress Levels in Exhaled Breath Condensate Associated With COPD and Smoking
}

\author{
Handan Inonu MD, Sibel Doruk MD, Semsettin Sahin MD, Unal Erkorkmaz PhD, \\ Deniz Celik MD, Serhat Celikel MD, and Zehra Seyfikli MD
}

\begin{abstract}
BACKGROUND: COPD is characterized by chronic air-flow limitation. Smoking is the most important factor in the pathogenesis of COPD. Smoking is associated with increased oxidative stress in the lungs. In this study our aim was to evaluate the differences in the burden of oxidative stress in patients with COPD, smokers, and non-smokers by measuring hydrogen peroxide $\left(\mathrm{H}_{2} \mathrm{O}_{2}\right)$, malondialdehyde (MDA), and 8-isoprostane levels in the exhaled breath condensate (EBC) samples. METHODS: Eighty subjects were included in the study. Group I (no. $=25$ ) had COPD, Group II (no. = 26) was smokers, and Group III (no. $=29$ ) was nonsmokers. The severity of the COPD and dyspnea was assessed according to the results of pulmonary function tests (PFTs) and Medical Research Council (MRC) scale. RESULTS: The mean age of the subjects was $58 \pm 8.9$ years. While 8-isoprostane and $\mathrm{H}_{2} \mathrm{O}_{2}$ levels were significantly higher in subjects with COPD $(44.8 \pm 40.2 \mathrm{pg} / \mathrm{mL}$ and $1.9 \pm 0.8 \mu \mathrm{mol} / \mathrm{L})$ and smokers $(41.3 \pm 26 \mathrm{pg} / \mathrm{mL}$ and $1.7 \pm 0.7 \mu \mathrm{mol} / \mathrm{L})$ than non-smokers $(15.8 \pm 6.9 \mathrm{pg} / \mathrm{mL}$ and $0.8 \pm 0.4 \mu \mathrm{mol} / \mathrm{L})$, levels were similar between smokers and COPD subjects. MDA levels were similar between the 3 groups $(P=.31)$. There was no correlation between 8-isoprostane and $\mathrm{H}_{2} \mathrm{O}_{2}$ levels and PFT parameters. There was a significant positive correlation between dyspnea grade on the MRC scale and 8-isoprostane levels $(r=0.805, P<.001)$. CONCLUSIONS: Even if respiratory function tests are within normal limits, oxidant burden in lungs of smokers is equivalent to that in COPD patients. 8-isoprostane could be useful in assessing symptom severity and health status of COPD patients. Key words: oxidative stress; smoking; hydrogen peroxide; malondialdehyde; 8-isoprostane. [Respir Care 2012;57(3):413-419. (C) 2012 Daedalus Enterprises]
\end{abstract}

\section{Introduction}

Chronic obstructive pulmonary disease (COPD) is characterized by chronic air-flow limitation associated with the inflammatory process of the lung. ${ }^{1}$ Smoking is the most important factor in the pathogenesis of COPD. ${ }^{2}$ Smoking

\footnotetext{
Drs Inonu, Doruk, Celik, Celikel, and Seyfikli are affiliated with the Department of Pulmonary Diseases; Dr Sahin is affiliated with the Department of Biochemistry; and Dr Erkorkmaz is affiliated with the Department of Biostatistics, Gaziosmanpasa University Faculty of Medicine, Tokat, Turkey.

The authors have disclosed no conflicts of interest.
}

Correspondence: Handan Inonu MD, Department of Pulmonary Diseases, Gaziosmanpasa University Faculty of Medicine, Taşlıçiftlik Yerleşkesi, Tokat, Turkey 60250. E-mail: handaninonu@gmail.com.

DOI: $10.4187 /$ respcare.01302 is associated with increased oxidative stress in the lungs. ${ }^{3}$ Smoking has been estimated to contain between $10^{16}-10^{17}$ oxidant molecules per puff. ${ }^{4}$ Increased oxidative stress is an important pathway in COPD. The sources of oxidative stress in COPD are inhaled oxidants and increased amounts of reactive oxygen species (ROS) generated by inflammatory cells involved in the pathophysiology of the disease. ${ }^{5}$ ROS may alter remodeling of extracellular matrix and blood vessels, stimulate mucus secretion, inactivate antiproteases, cause apoptosis, and regulate cell proliferation. ${ }^{6}$

Collection of exhaled breath condensate (EBC) has been suggested as a simple, noninvasive, and easily repeatable procedure, and samples from the lower respiratory tract for monitoring airway inflammation and oxidative stress can be obtained with this technique. ${ }^{7}$ Several oxidative stress markers are measurable in EBC. ${ }^{8}$ The tar phase of smoke contains the hydroxyl radical $(\mathrm{OH})$ and hydrogen peroxide $\left(\mathrm{H}_{2} \mathrm{O}_{2}\right) \cdot{ }^{9} \mathrm{H}_{2} \mathrm{O}_{2}$ is a direct marker of air-space oxidative burden and measurable in EBC. ${ }^{5}$ Isoprostanes are pro- 
duced by ROS mediated peroxidation of arachidonic acid. The levels of 8-isoprostane in EBC have been shown to be elevated in healthy smokers. ${ }^{10}$ Malondialdehyde (MDA) is a toxic product associated with lipid peroxidation. ${ }^{11}$ The measurement of MDA in biological fluids is a widely used test for determination of oxidative stress. ${ }^{12}$

In this study our aim was to evaluate the differences in the burden of oxidative stress in patients with COPD, smokers, and non-smokers by measuring $\mathrm{H}_{2} \mathrm{O}_{2}$, MDA, and 8-isoprostane levels in the EBC samples. Our second aim was to evaluate whether there is an association between the levels of these markers and the severity and duration of the COPD.

\section{Methods}

\section{Subjects}

We included totally 80 male subjects as 3 groups in the study. Women were not included in the study because oxidative stress levels differ significantly by sex. The subjects in Group I (no. = 25) had COPD (all ex-smokers), Group II (no. $=26$ ) were smokers, and Group III (no. $=29$ ) were nonsmokers. Group II and Group III were constituted of healthy subjects. The classification of the COPD subjects was performed according to the Global Initiative for Chronic Obstructive Lung Disease (GOLD) guideline. ${ }^{1}$ Patients with COPD were evaluated during a stable period. Disease severity was assessed according to the results of pulmonary function tests (PFTs), and severity of dyspnea according to the Medical Research Council (MRC) scale. ${ }^{13}$ (in a scale of 0 to 4 as follows):

0 . Not troubled by breathlessness except on strenuous exercise

1. Shortness of breath when hurrying on the level or walking up a slight hill

2. Walks slower than people of the same age on the level because of breathlessness, or has to stop for breath when walking at own pace

3. Stops for breath after about $100 \mathrm{~m}$ or after a few minutes on the level

4. Too breathless to leave the house, or breathless when dressing or undressing

Duration of the disease and medical treatments were recorded. COPD subjects were treated with inhaled corticosteroids (budesonide 200-400 $\mu \mathrm{g} / \mathrm{d}$, fluticasone $500-$ $1,000 \mu \mathrm{g} / \mathrm{d}$ ), inhaled $\beta$-adrenergic agonists, and theophylline. Patients with a history of atopy or positive skin prick testing for common inhaled allergens; history of asthma or other respiratory diseases; and systemic diseases such as diabetes mellitus, collagen vascular diseases, inflammatory bowel diseases, coronary artery diseases, and chronic renal failure; take oral or inhaled $\mathrm{N}$-acetylcysteine or vitamin $\mathrm{C}$ and/or E; or showed bronchial hyper-reactivity or

\section{QUICK LOOK}

\section{Current knowledge}

Cigarette smoking is associated with increased oxidative stress in the lungs. This can be measured as hydrogen peroxide and 8-isoprostane in exhaled breath condensate.

\section{What this paper contributes to our knowledge}

The oxidative stress associated with cigarette smoking is similar in the lungs of patients with and without COPD. Oxidative stress markers may be helpful in monitoring symptoms and lung health in patients with COPD.

an acute response in $\mathrm{FEV}_{1}$ to inhaled bronchodilator of more than $15 \%$ of predicted values were excluded from the study. Chest radiography was carried out to exclude other respiratory diseases. Subjects with COPD were clinically stable, with no worsening of symptoms, need of increase of medication, emergency care, or hospitalization within the previous 4 weeks. Healthy smoker subjects were asked to refrain from smoking for at least 6 hours before starting the study. The ethics committee of Gaziosmanpasa University Hospital, Tokat, Turkey, approved the study protocol, and all subjects gave written informed consent before participating.

\section{Pulmonary Function Tests}

PFTs were performed to diagnose COPD and to determine any differences between the groups. Spirometry was performed after the administration of an inhaled bronchodilator (400 $\mu \mathrm{g}$ salbutamol). FVC, $\mathrm{FEV}_{1}, \mathrm{FEV}_{1} / \mathrm{FVC}$, and maximum mean expiratory flow were expressed in milliliters and percentage of the predicted value, using a dry spirometer (MasterScreen Pneumo, Erich Jaeger, Würzburg, Germany), and the best value of 3 maneuvers was expressed as a percentage of the predicted value. ${ }^{14}$ The results of a reversibility test were used. All the subjects with COPD had airways obstruction with $\mathrm{FEV}_{1}<80 \%$ predicted and $\mathrm{FEV}_{1} / \mathrm{FVC}<70 \%$, and a history of chronic progressive symptoms such as dyspnea, cough, and sputum production.

\section{Collection of Exhaled Breath Condensate}

EBCs were collected using a condenser (EcoScreen, Erich Jaeger, Würzburg, Germany). Subjects breathed through a mouthpiece and a 2-way non-rebreathing valve, which also served as a saliva trap. Analysis of salivary amylase concentrations in EBC is a frequently used method to reflect saliva contamination in EBC. According to the 
American Thoracic Society/European Respiratory Society task force, there is no need to determine amylase levels in EBC samples, but efforts should be made to prevent salivary contamination. ${ }^{15}$ Before the measurement the patients rinsed their mouths with water. The subjects were asked to breathe at a normal frequency and tidal volume, wearing a nose clip, for a period of $15 \mathrm{~min}$. The collected condensate from each patient was at least $2 \mathrm{~mL}$, which was immediately stored at $-70^{\circ} \mathrm{C}$. Samples were stored for 6 months. All EBC samples were collected at same time of day, between 2 PM to 4 PM.

\section{Quantitative Analyses of Oxidants in Exhaled Breath Condensate}

8-Isoprostane. 8-Isoprostane samples were prepared using an 8-isoprostane EIA (enzyme immunoassay) commercial kit (catalog no. 516351, Cayman Chemical, Ann Arbor, Michigan) and measured by EIA method.

Hydrogen Peroxide. Hydrogen peroxide samples were prepared using a hydrogen peroxide assay commercial kit (catalog no. 706011, Cayman Chemical, Ann Arbor, Michigan), and measured at $595 \mathrm{~nm}$ by colorimetric assay (detection range $11-66 \mu \mathrm{M})$.

Malondialdehyde. MDA samples were prepared with commercial kit (Recipe ClinRep Complete, IRIS Technologies International, Cursdorf, Germany), and measured in a fluorescent detector by high performance liquid chromatography (RF-10AXL, Shimadzu, Kyoto, Japan) method (detection limit $0.02 \mu \mathrm{mol} / \mathrm{L}$, detection range $0.04-$ $20 \mu \mathrm{mol} / \mathrm{L})$.

\section{Statistical Analysis}

Statistical power of the sample was calculated as $91 \%$, assuming the effect size of 8-isoprostane and $\mathrm{H}_{2} \mathrm{O}_{2}$ measurements as 0.55 . Chi-square tests were used to compare the categorical variables between groups. The KolmogorovSmirnov test was used to evaluate whether the distribution of variables was normal. One-way analysis of variance was used to compare the continuous variables among 3 groups. For multiple comparisons of analysis of variance, the Tukey honest significant difference test was used. The Pearson correlation coefficient was used to determine the correlations between continuous variables. Continuous variables were presented as arithmetical mean and standard deviation. A 2-tailed $P$ value of $<.05$ was considered statistically significant. Analyses were performed using commercially available software (PASW 18, SPSS. Chicago, Illinois).
Table 1. PFTs of the Study Groups $(n=80)$

\begin{tabular}{|c|c|c|c|c|}
\hline & $\begin{array}{c}\text { Group I } \\
(\text { COPD) } \\
(\text { no. }=25)\end{array}$ & $\begin{array}{l}\text { Group II } \\
(\text { Smokers) } \\
(\text { no. }=26)\end{array}$ & $\begin{array}{c}\text { Group III } \\
\text { (Non-Smokers) } \\
(\text { no. }=29)\end{array}$ & $P$ \\
\hline $\mathrm{FEV}_{1}(\mathrm{~L})$ & $1.7 \pm 0.5$ & $2.9 \pm 0.7$ & $3.4 \pm 0.5$ & $<.001^{*}$ \\
\hline FVC (L) & $2.9 \pm 0.7$ & $3.5 \pm 0.9$ & $4.2 \pm 0.7$ & $<.001^{*}$ \\
\hline $\mathrm{FEV}_{1} / \mathrm{FVC}(\%)$ & $57.8 \pm 7.3$ & $83 \pm 8.5$ & $80.2 \pm 5.9$ & $<.001 \dagger$ \\
\hline MMEF (L) & $0.7 \pm 0.3$ & $3 \pm 1.3$ & $3.2 \pm 1.2$ & $<.001 \dagger$ \\
\hline \multicolumn{5}{|c|}{$\begin{array}{l}\text { Values are mean } \pm \mathrm{SD} \text {. } \\
\text { * There was statistically significant differences between all pair-wise comparisons. } \\
\dagger \text { There was statistically significant differences between group I and other groups, but no } \\
\text { statistically significant differences between group II and groups III. } \\
\text { PFT = pulmonary function test } \\
\text { MMEF = maximum mean expiratory flow }\end{array}$} \\
\hline
\end{tabular}

Table 2. Levels of Oxidants in Groups

\begin{tabular}{lcccc}
\hline \hline & $\begin{array}{c}\text { Group I } \\
(\text { COPD }) \\
(\text { no. }=25)\end{array}$ & $\begin{array}{c}\text { Group II } \\
(\text { Smokers }) \\
(\text { no. }=26)\end{array}$ & $\begin{array}{c}\text { Group III } \\
(\text { Non-Smokers }) \\
(\text { no. }=29)\end{array}$ & $P$ \\
\hline $\begin{array}{c}\text { Malondialdehyde } \\
(\mu \mathrm{mol} / \mathrm{L})\end{array}$ & $0.08 \pm 0.01$ & $0.08 \pm 0.02$ & $0.08 \pm 0.02$ & .31 \\
$\begin{array}{c}\text { 8-isoprostane } \\
(\mathrm{pg} / \mathrm{mL})\end{array}$ & $44.8 \pm 40.2$ & $41.3 \pm 26$ & $15.8 \pm 6.9$ & $<.001$ \\
$\mathrm{H}_{2} \mathrm{O}_{2}(\mu \mathrm{mol} / \mathrm{L})$ & $1.9 \pm 0.8$ & $1.7 \pm 0.7$ & $0.8 \pm 0.4$ & .003 \\
\hline Values are mean $\pm \mathrm{SD}$. & & & & \\
\hline
\end{tabular}

\section{Results}

A total of 80 male subjects in 3 groups, with a mean age of $58 \pm 8.9$ years, were included in the study. Group I included 25 COPD patients (all ex-smokers) (mean packyears $34 \pm 2$ ). Mean COPD disease duration was $25 \pm 4$ years. Group II included 26 healthy subjects who were current smokers (mean pack-years $32 \pm 3$ ). Subjects with COPD and healthy smokers were matched for smoking habits $(P>.05)$. Subjects with COPD had stopped smoking for at least 12 months. Twenty-nine individuals (never-smokers) were included into the study as Group III. Study groups were matched for age (63.3 $\pm 7 \mathrm{y}$ in COPD, $61.2 \pm 6 \mathrm{y}$ in smokers, $60 \pm 8 \mathrm{y}$ in non-smokers, $P=.13$ ). The PFTs of the study groups are seen in Table 1.

While 8-isoprostane and $\mathrm{H}_{2} \mathrm{O}_{2}$ levels were significantly higher in subjects with COPD and smokers than in nonsmokers, levels were similar between smokers and subjects with COPD. There was no difference between the groups according to the levels of MDA (Tables 2 and 3, Figs. 1, 2, and 3).

There was no correlation between 8-isoprostane and $\mathrm{H}_{2} \mathrm{O}_{2}$ levels and PFT parameters $(P>.05)$. There was a significant positive correlation between dyspnea grade on the MRC scale and 8-isoprostane levels $(r=0.805$, 
Table 3. Multiple Comparisons for Analysis of Variance

\begin{tabular}{lccc}
\hline \hline & \multicolumn{3}{c}{ Comparison Results $(P$ values $)$} \\
\cline { 2 - 4 } & $\begin{array}{c}\text { Group } \\
\text { I and III }\end{array}$ & $\begin{array}{c}\text { Group } \\
\text { I and II }\end{array}$ & $\begin{array}{c}\text { Group } \\
\text { II and III }\end{array}$ \\
\hline 8-isoprostane $(\mathrm{pg} / \mathrm{mL})$ & .005 & .978 & $<.001$ \\
$\mathrm{H}_{2} \mathrm{O}_{2}(\mu \mathrm{mol} / \mathrm{L})$ & $<.001$ & .743 & $<.001$ \\
\hline
\end{tabular}

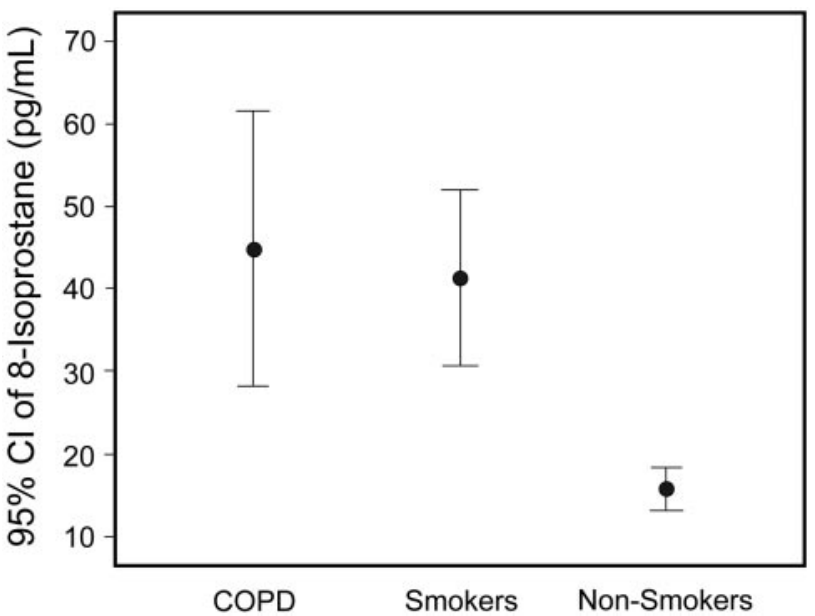

Fig. 1. 8-isoprostane levels in the study groups.

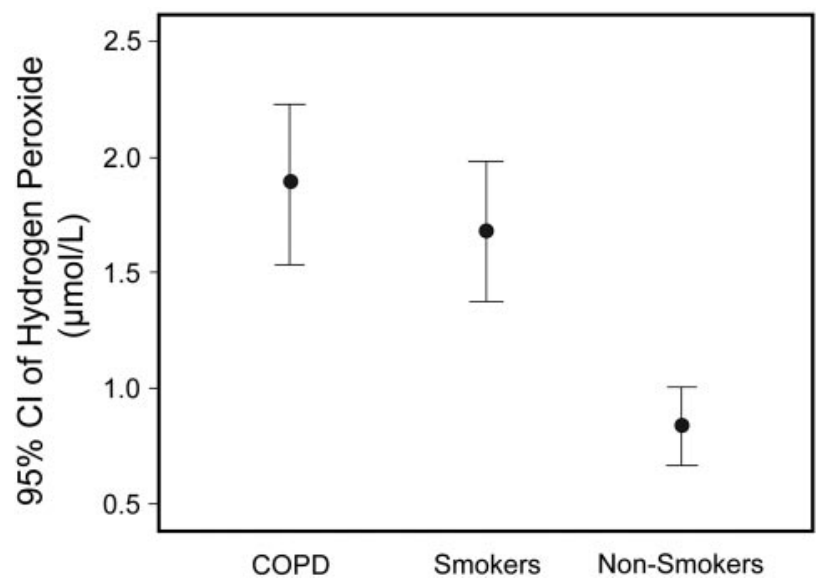

Fig. 2. $\mathrm{H}_{2} \mathrm{O}_{2}$ levels in the study groups.

$P<.001$ ) (Fig. 4). There was a significant positive correlation between duration of COPD and levels of MDA ( $\mathrm{r}=0.518, P=.008$ ) (Fig. 5). The levels of $\mathrm{MDA}, \mathrm{H}_{2} \mathrm{O}_{2}$, 8 -isoprostane were similar in COPD subjects treated with $($ no. $=6)$ or without $($ no. $=19)$ inhaled corticosteroids (ICSs) $(P>.05)$.

\section{Discussion}

In this study, where pulmonary oxidative loads in smokers, non-smokers, and in subjects with COPD were com-

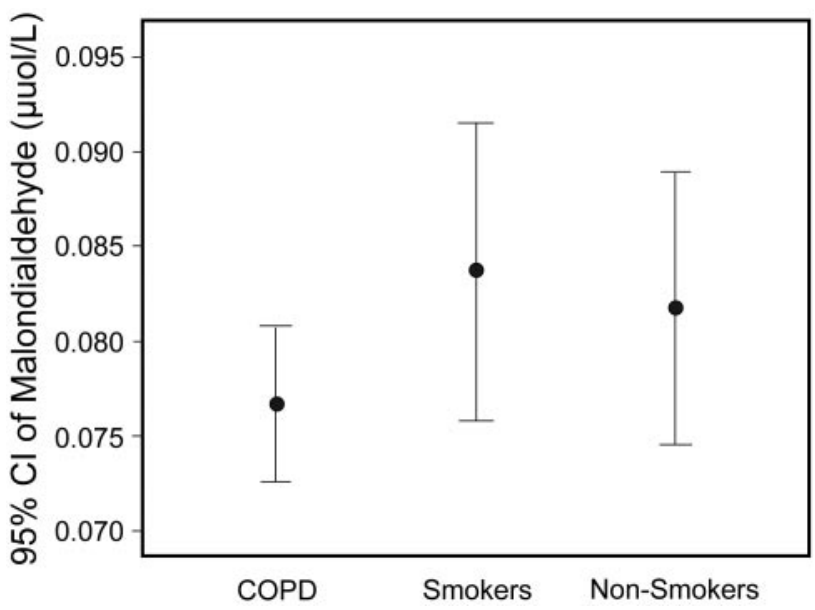

Fig. 3. Malondialdehyde levels in the study groups.

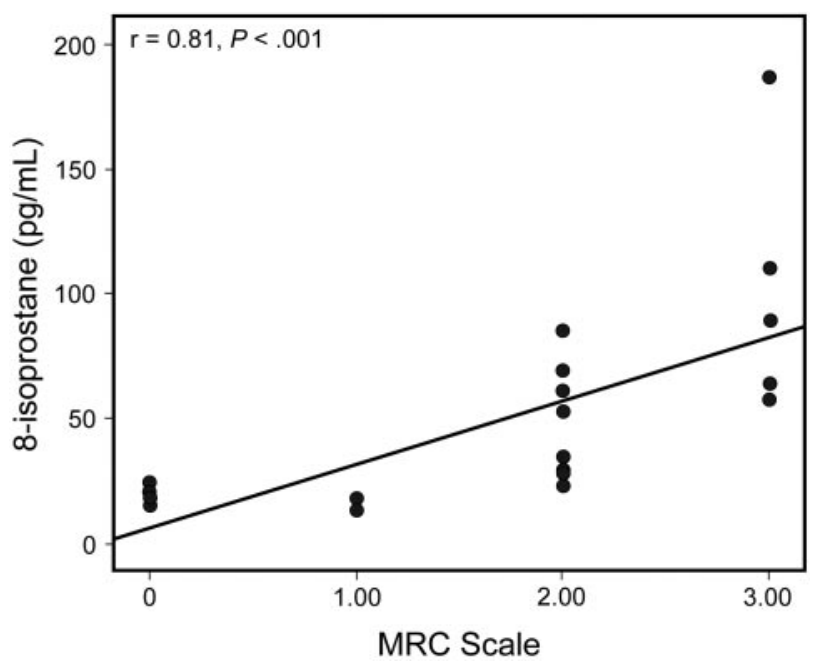

Fig. 4. The correlation of 8-isoprostane levels and Medical Research Council (MRC) scale.

pared, levels of 8-isoprostane and $\mathrm{H}_{2} \mathrm{O}_{2}$ in $\mathrm{EBC}$ of smokers were found to be higher than those detected in nonsmokers, but similar to the levels in cases with COPD. This outcome might indicate that in smokers without any evidence of COPD, intensive pulmonary oxidative stress can develop similar to that seen in cases with COPD. Oxidant-mediated lung injury is important in the pathogenesis of smoking-induced lung disease. Smoke contains high concentrations of ROS. ${ }^{6}$ Increased levels of ROS in the airways and lungs following inhalation of smoke are associated directly with oxidants in the smoke, and also indirectly from the release of ROS by macrophages and neutrophils infiltrating the lungs. ROS can also stimulate inflammatory cells. Products of activated lung macrophages and neutrophils promptly propagate to lung epithelial and endothelial cells, leading to tissue damage. ${ }^{5}$ This excess 


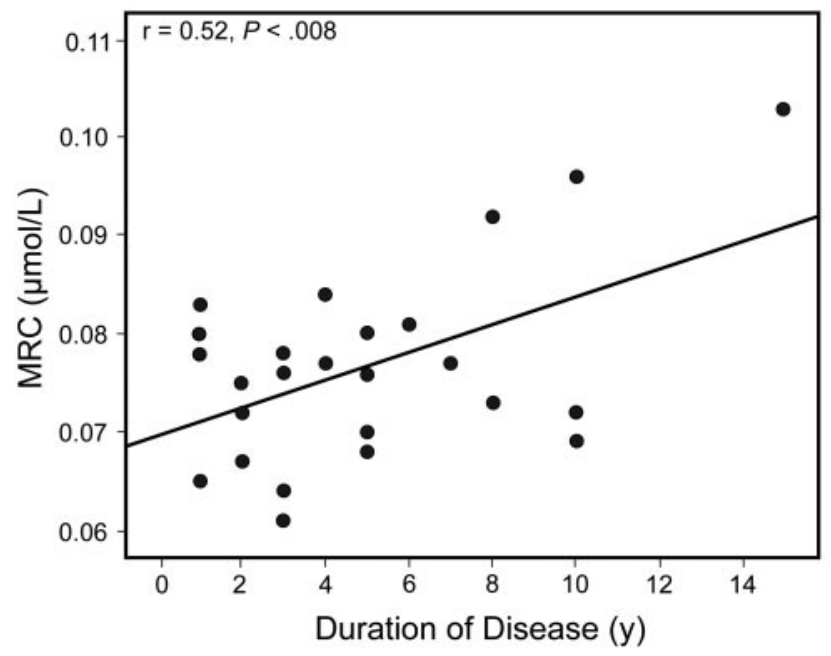

Fig. 5. The correlation of Medical Research Council (MRC) scale and duration of disease.

ROS disturbs the balance between oxidants and antioxidants, resulting in oxidative stress. ${ }^{16}$

Induced sputum, bronchoalveolar lavage fluid, or bronchial biopsy are among the invasive methods used for direct assessment of airway inflammation. EBC obtained by cooling exhaled air during spontaneous breathing is a simple, safe, and noninvasive method. This technique provides samples from the lower respiratory tract to assess airway inflammation and oxidative stress. ${ }^{15}$ Several oxidative stress markers are measurable in EBC. ${ }^{8}$ In this study we aimed to detect the differences in the burden of oxidative stress in subjects with COPD, smokers, and nonsmokers via measurement of the levels of $\mathrm{MDA}, \mathrm{H}_{2} \mathrm{O}_{2}$, and 8-isoprostane in EBC.

Isoprostanes are produced by ROS mediated peroxidation of arachidonic acid. The increased levels of 8-isoprostane observed in smokers in this study are similar to previously reported findings. ${ }^{6,17}$ Various levels of 8-isoprostane in EBC of smokers have been mentioned in the literature. EBC 8-isoprostane levels in healthy smokers were reported to be $24 \mathrm{pg} / \mathrm{mL}$, and $49.9 \mathrm{pg} / \mathrm{mL}$ by Montuschi et $\mathrm{al}^{10}$ and Borrill et al, ${ }^{17}$ respectively. In our study, the mean concentration of 8-isoprostane in EBC of smokers was $41.3 \mathrm{pg} / \mathrm{mL}$. These variable results of measurements of 8-isoprostane in EBC probably reflect differences between acute and chronic effects of smoking.

In one study, the levels of 8-isoprostane in stable COPD subjects were higher than healthy controls and lower than cases with exacerbation of COPD. ${ }^{18}$ In our study, 8-isoprostane levels were higher in subjects with COPD than non-smokers, but levels were similar between subjects with COPD and smokers. This outcome might indicate that in smokers without any evidence of COPD, intensive pulmonary oxidative stress can develop similar to that seen in cases with COPD, suggestive of the presence of a dam- aged pulmonary parenchyma. In a study conducted by Makris et al, a correlation between levels of 8-isoprostane, parenchymal alterations in high-resolution computed tomography, and the prevalence of emphysema had been demonstrated. ${ }^{19}$

We assessed the clinical severity of COPD using respiratory symptoms and PFT parameters. The severity of respiratory symptoms was assessed by MRC scale as an objective measurement method. We found that 8-isoprostane levels were significantly associated with MRC scale. This result suggests that EBC 8-isoprostane could be a useful marker in assessing symptomatic severity and health status of COPD patients.

In this study we did not detect any correlation between 8-isoprostane and $\mathrm{H}_{2} \mathrm{O}_{2}$ levels and $\mathrm{FEV}_{1}$, in accordance with previous studies. ${ }^{19,20}$ An explanation to that could be that $\mathrm{FEV}_{1}$ and 8-isoprostane are different markers in the pathophysiology of COPD. Whereas $\mathrm{FEV}_{1}$ reflects broadly airway caliber, 8-isoprostane reflects oxidative stress. Indeed, in our study, comparatively higher levels of 8-isoprostane were detected in smokers, despite absence of serious airway obstruction.

$\mathrm{H}_{2} \mathrm{O}_{2}$ is a direct measurement of air-space oxidative burden. ${ }^{5}$ The source of increased $\mathrm{H}_{2} \mathrm{O}_{2}$ is unknown, but may be in part derived from increased release of $\mathrm{O}_{2}{ }^{-}$from alveolar macrophages of smokers. ${ }^{6}$ In this study, higher levels of $\mathrm{H}_{2} \mathrm{O}_{2}$ were observed in smokers than nonsmokers, but levels were similar between smokers and COPD subjects. This result showed that oxidant burden in lungs of healthy smokers is equivalent to COPD subjects. Many different outcomes have been reported on the effects of ICS treatment on the levels of exhaled $\mathrm{H}_{2} \mathrm{O}_{2}$. One study showed no effect of treatment with beclomethasone on $\mathrm{H}_{2} \mathrm{O}_{2}$ concentrations in EBC. ${ }^{21}$ In contrast, another study reported that ICSs reduced exhaled $\mathrm{H}_{2} \mathrm{O}_{2}$ in subjects with stable COPD. ${ }^{22}$ In our study, COPD subjects receiving ICS therapy had similar $\mathrm{H}_{2} \mathrm{O}_{2}$ values, compared with steroid-naive subjects. According to this result, one might conceive that ICSs suppress inflammatory processes contributing to alleviation of oxidative stress. On the other hand, the lack of difference between the groups might be a result of sample size.

Steroids inhibit the synthesis of pro-inflammatory cytokines in inflammatory cells, may reduce the number of activated cells that release pro-inflammatory cytokines, and thus reduce the production of $\mathrm{H}_{2} \mathrm{O}_{2} \cdot{ }^{22}$ ICS or oral steroids significantly reduce the chemotactic activity of neutrophils and increase the neutrophil elastase inhibitory capacity in induced sputum. ${ }^{23,24}$ In addition, evidence from in vitro studies suggests that among the anti-inflammatory actions of steroids there is a reduction in the generation of ROS by neutrophils. ${ }^{25}$

Acute smoke exposure increases the products of lipid peroxidation. ${ }^{26} \mathrm{MDA}$ is a toxic product associated with 


\section{Oxidative Stress Levels in Exhaled Breath Condensate}

lipid peroxidation. ${ }^{11} \mathrm{~A}$ widely used test for oxidative stress is the measurement of MDA in biological fluids. ${ }^{12}$ MDA can be measured as a thiobarbituric acid-reactive substance in EBC. ${ }^{27}$ Increased MDA levels has been reported in smokers. ${ }^{16,28}$ Corradi et al reported that MDA levels were increased in subjects with COPD in comparison to both non-smoking and smoking control subjects. ${ }^{29}$ We did not detect any difference between the levels of MDA between groups. There was a significantly positive correlation between COPD disease duration and MDA levels.

The limitations of this study were: some markers analyzed in EBC show diurnal variations. Repeated measurements at different hours in a day could improve the reliability of the results. Repeated measurements were not used in our study, but all EBC samples were taken at the same time of day to avoid possible differences due to diurnal changes.

Comparing COPD subjects with both healthy smokers and healthy non-smokers is a strength of this study. Most of the studies in the literature evaluated oxidative stress levels in COPD subjects compared with healthy smokers or compared with healthy non-smokers. Another important point is that women were not included in the study, to exclude changes caused by sex differences, so the study group was more homogeneous.

\section{Conclusions}

In conclusion, smoking affects the levels of many oxidant markers in the lungs. $\mathrm{H}_{2} \mathrm{O}_{2}$ and 8 -isoprostane may be useful markers of oxidative stress in the lung inflammation induced by exposure to smoking. In addition, 8-isoprostane could be useful in assessing symptom severity and health status of COPD patients. Even if respiratory function tests are within normal limits, oxidant burden in lungs of smokers is equivalent to COPD patients.

\section{REFERENCES}

1. Global Initiative for Chronic Obstructive Lung Disease (GOLD). Global strategy for the diagnosis, management, and prevention of chronic obstructive pulmonary disease. GOLD report, updated December $2011 \mathrm{http} / / / \mathrm{www}$.goldcopd.org/guidelines-global-strategyfor-diagnosis-management.html. Accessed December 30, 2011.

2. Sethi JM, Rochester CL. Smoking and chronic obstructive pulmonary disease. Clin Chest Med 2000;21(1):67-86.

3. Rahman I, W MacNee. Role of oxidants/antioxidants in smokinginduced lung diseases. Free Radic Biol Med 1996;21:669-681.

4. Church T, WA Pryor. Free-radical chemistry of cigarette smoke and its toxicological implications. Environ Health Perspect 1985;64:111-126.

5. Mak JC. Pathogenesis of COPD. Part II. Oxidative-antioxidative imbalance. Int J Tuberc Lung Dis 2008;12(4):368-374.

6. Rahman I. The role of oxidative stress in the pathogenesis of COPD: implications for therapy. Treat Respir Med 2005;4(3):175-200.

7. Kharitonov SA, Barnes PJ. Exhaled markers of pulmonary diseases. Am J Respir Crit Care Med 2001;163(7):1693-1722.
8. Romieu I, Barraza-Villarreal A, Escamilla-Nuñez C, Almstrand AC, Diaz-Sanchez D, Sly PD, Olin AC. Exhaled breath malondialdehyde as a marker of effect of exposure to air pollution in children with asthma. J Allergy Clin Immunol 2008;121(4):903-909.

9. Pryor WA, K Stone. Oxidants in cigarette smoke: radicals, hydrogen peroxides, peroxynitrate, and peroxynitrite. Ann NY Acad Sci 1993; 686:12-28.

10. Montuschi P, Collins JV, Ciabattoni G, Lazzeri N, Corradi M, Kharitonov SA, Barnes PJ. Exhaled 8-isoprostane as an in vivo biomarker of lung oxidative stress in patients with COPD and healthy smokers. Am J Respir Crit Care Med 2000;162(3 Pt 1):1175-1177.

11. Abuja PM, Albertini R. Methods for monitoring oxidative stress, lipid peroxidation and oxidation resistance of lipoproteins. Clin Chim Acta 2001;360(1-2):1-17.

12. Gutteridge JM, Halliwell B. The measurement and mechanism of lipid peroxidation in biological systems. Trends Biochem Sci 1990; 15(4):129-135.

13. Global Initiative for Chronic Obstructive Pulmonary Disease. 2001 original: pocket guide to COPD diagnosis, management, and prevention. Developed from the NHLBI/WHO Workshop Report, global strategy for the diagnosis, management and prevention of COPD. http://www.goldcopd.org/Guidelines/guideline-2001-original\%3apocket-guide-to-copd-diagnosis $\% 2 \mathrm{c}$-management $\% 2 \mathrm{c}$-andprevention.html. Accessed December 30, 2011.

14. Quanjer PH, Tammeling GJ, Cotes JE, Pedersen OF, Peslin R, Yernault JC. Lung volumes and forced ventilatory flows. Report Working Party Standardization of Lung Function Tests, European Community for Steel and Coal. Official Statement of the European Respiratory Society. Eur Respir J 1993;16(Suppl):5-40.

15. Horváth I, Hunt J, Barnes PJ, Alving K, Antczak A, Baraldi E, et al. Exhaled breath condensate: methodological recommendations and unresolved questions. ATS/ERS Task Force. Eur Respir J 2005; 26(3):523-548.

16. Valenca SS, Silva Bezerra F, Lopes AA, Romana-Souza B, Marinho Cavalcante MC, Lima AB, et al. Oxidative stress in mouse plasma and lungs induced by cigarette smoke and lipopolysaccharide. Environ Res 2008;108(2):199-204.

17. Borrill ZL, Roy K, Vessey RS, Woodcock AA, Singh D. Noninvasive biomarkers and pulmonary function in smokers. Int J Chron Obstruct Pulmon Dis 2008;3(1):171-183.

18. Pinamonti S, Muzzoli M, Chicca MC, Papi A, Ravenna F, Fabbri LM, Ciaccia A. Xanthine oxidase activity in bronchoalveolar lavage fluid from patients with chronic obstructive pulmonary disease. Free Radic Biol Med 1996;21(2):147-155.

19. Makris D, Paraskakis E, Korakas P, Karagiannakis E, Sourvinos G, Siafakas NM, Tzanakis N. Exhaled breath condensate 8-isoprostane, clinical parameters, radiological indices and airway inflammation in COPD. Respiration 2008;75(2):138-144.

20. Kostikas K, Papatheodorou G, Ganas K, Psathakis K, Panagou P, Loukides S. pH in expired breath condensate of patients with inflammatory airway diseases. Am J Respir Crit Care Med 2002; 165(10):1364-1370.

21. Ferreira IM, Hazari MS, Gutierrez C, Zamel N, Chapman KR. Exhaled nitric oxide and hydrogen peroxide in patients with chronic obstructive pulmonary disease: effects of inhaled beclomethasone. Am J Respir Crit Care Med 2001;164(6):1012-1015.

22. van Beurden WJ, Harff A, Dekhuijzen PN, van der Poel-Smet SM, Smeenk FW. Effects of inhaled corticosteroids with different lung deposition on exhaled hydrogen peroxide in stable COPD patients. Respiration 2003;70(3):242-248.

23. Llewellyn-Jones CG, Harris TA, Stockley RA. Effect of fluticasone propionate on sputum of patients with chronic bronchitis and emphysema. Am J Respir Crit Care Med 1996;153(2):616-621. 


\section{Oxidative Stress Levels in Exhaled Breath Condensate}

24. Stockley RA, Morrison HM, Kramps JA, Dijkman JH, Burnett D. Elastase inhibitors of sputum sol phase: variability, relationship to neutrophils elastase inhibition, and effect of corticosteroids treatment. Thorax 1986;41(6):442-447.

25. Goldstein IM, Roos D, Kaplan HB. Influence of corticosteroids on human polymorphonuclear leukocytes function in vitro. Inflammation 1976;1:305-315.

26. van der Vaart H, Postma DS, Timens W, ten Hacken NH. Acute effects of cigarette smoke on inflammation and oxidative stress: a review. Thorax 2004;59(8):713-721.
27. Nowak D, Kalucka S, Bialasiewicz P, Król M. Exhalation of $\mathrm{H}_{2} \mathrm{O}_{2}$ and thiobarbituric acid reactive substances (TBARs) by healthy subjects. Free Radic Biol Med 2001;30(2):178-186.

28. Bloomer RJ. Decreased blood antioxidant capacity and increased lipid peroxidation in young cigarette smokers compared to nonsmokers: Impact of dietary intake. Nutr J 2007;39:1-6.

29. Corradi M, Rubinstein I, Andreoli R, Manini P, Caglieri A, Poli D, et al. Aldehydes in exhaled breath condensate of patients with chronic obstructive pulmonary disease. Am J Respir Crit Care Med 2003; 167(10):1380-1386. 